\title{
Application of Probability Theory in Social Hotspot and Its Role in Teaching
}

\author{
Rui Chen ${ }^{1}$ and Liang Fang, ${ }^{2, *}$ \\ ${ }^{1}$ College of Mathematics and Statistics, Taishan University, 271000, Tai'an, China \\ ${ }^{2}$ College of Mathematics and Statistics, Taishan University, 271000, Tai'an, China \\ ${ }^{*}$ Corresponding author
}

\begin{abstract}
This paper first introduces the origin and application of probability theory, and puts forward the idea of letting the social hot spot application of probability theory penetrate into its teaching, then introduces the knowledge points commonly used in probability theory and the current social hot issues, explains the application of probability theory knowledge in social hot issues.
\end{abstract}

Keywords-probability theory; social hotspots; application; teaching

\section{INTRODUCTION}

\section{A. The Origin of Probability Theory}

Every science, technology and theory needs to be connected to social life; new technologies and theories can only be advanced if there are new problems and motives in society. The first questions of probabilistic nature, it also originates from various fields of human life, such as property insurance, marine insurance, life insurance, etc. Although insurance came early, but before the 14th century, property, shipping and life insurance did not promote random ideas and statistical concepts, so it's only in the bud. It was the ancient game of opportunity that really contributed directly to the birth of probability theory, the gist of the concept of probability was established in the discussion between Pascal and Fermat in the mid-17th century. Their exchange of letters, in which they discussed and resolved the issue of reasonable allocation of bets, marked the birth of probability theory [1].

\section{B. The Application of Probability Theory}

Since the 20th century, thanks to the development of physics, biology, engineering, agriculture and military technology, the theory of probability is developing rapidly, the theoretical subjects are expanding and deepening, and the scope of application is greatly expanded. In recent decades, the approach of probability theory has been introduced into various engineering and social disciplines. At present, probability theory has been applied in modern physics, automatic control, earthquake prediction and weather forecast, quality control of factory products, agricultural experiment and public utilities. More and more methods of probability theory have been introduced into economic, financial and management science and probability theory has become a powerful tool for them.

\section{THE APPLICATION OF PROBABILITY THEORY AND ITS PENETRATION IN TEACHING}

\section{A. Binomial Distribution and Poisson Distribution}

Recently, "student lotteries" were selling at school Gates, which value 50 cents per sheet and the odds are one percent. There is no consideration of the grade of the prize, only the effect of winning or not on the students purchasing psychology. Since the odds are one percent, I bought 100 of them, but I didn't win. If someone else buys 10, how can they win? With this mentality, the kids are selling more. This social hotspot problem can be solved by using binomial distribution and Poisson distribution for approximate calculation.

Because every time you buy a lottery ticket, it's independent. We make $X$ mean number of winners, make $n$ mean number of purchases; we know $X \sim b(n, 0.01)$. The probability of at least one winning is approximated by Poisson distribution:

$$
\begin{aligned}
P(X \geq 1) & =1-P(X=0) \\
& =1-0.99^{n} \approx 1-e^{-\lambda}(\lambda=0.01 n) .
\end{aligned}
$$

As $n$ changes, we have Table 1 [2].

TABLE I. THE RELATIONSHIP BETWEEN PURCHASE NUMBER AND AT LEAST 1 WINNING PROBABILITY

\begin{tabular}{cc}
\hline Number of sheets purchased & At least one winning shot \\
\hline$n=10$ & 0.0956 \\
$n=50$ & 0.3950 \\
$n=100$ & 0.6340 \\
$n=300$ & 0.9510 \\
$n=500$ & 0.9934 \\
$n=600$ & 0.9976 \\
\hline
\end{tabular}


The probability of buying 100 is 0.6340 , which means not necessarily winning. The probability of buying 10 is 0.0956 ; it's not 10 times as likely to buy 100 as 10 . And at a lottery sale, let's say people buy 10 tickets per person. At the same time, the number of people who bought the lottery was high. 500 or more are easy to achieve. So at least one winning shot is 0.9976 , that's why people always win the lottery, but that is not you. In addition, the reasons for the popularity of various lottery tickets are explained [3].

\section{B. Bayesian Formula and Central Limit Theorem}

- In cancer test, positive reaction must have cancer?

According to previous clinical records, some kind of diagnostic cancer trial, we make $A$ mean test positive, make $B$ mean diagnosed with cancer. We have

$$
P(A \mid B)=0.95, P(\bar{A} \mid \bar{B})=0.9 \text {. }
$$

Through investigations we make assumptions that the probability of the person tested had cancer is 0.0004 , namely $P(B)=0.0004$, find $P(B \mid A)=$ ?

By the Bayesian formula [4], we have

$$
\begin{aligned}
P( & B \mid A)=\frac{P(A \mid B) P(B)}{P(A \mid B) P(B)+P(A \mid \bar{B}) P(\bar{B})} \\
& =\frac{0.95 \times 0.0004}{0.95 \times 0.0004+(1-0.9)(1-0.0004)} \\
& \approx 0.0038 .
\end{aligned}
$$

Results show that although

$$
P(A \mid B)=0.95, P(\bar{A}) \mid \bar{B})=0.9
$$

but when someone tests positive, don't panic too much, because the probability of cancer is only 0.0038 , which may not be acceptable to a person who lacks probabilistic thinking.

Here's another intuitive solution to reassure people, because $P(B)=0.0004$, so on average only 4 out of 10,000 people have cancer, and $P(A \mid B)=0.95$, so 3.8 of the 4 people with cancer tested positive and 0.2 of the negative. Of the 9,996 persons who did not have cancer,

$$
9996 \times 0.1=999.6
$$

tested positive and 8,996.4 tested negative. Thus, of the 10,000 people who tested positive,

$$
3.8+9996=1003.4,
$$

of whom only 3.8 actually had cancer; so

$$
P(B \mid A)=\frac{3.8}{1003.4} \approx 0.0038
$$

This is consistent with the results. It's small because of the proportion of people who actually have cancer.

- How much is the true profit of the insurance company after lots of people are insured?

An insurance company shall start a one-year medical insurance business in which the insured person shall pay an annual premium of $\$ 100$, and shall receive an indemnity of $\$ 10,000$ in the event of a serious personal accident within one year. The probability of a major personal accident occurring in one year in the city is 0.005 . There are now 5000 people in the insurance. Ask the insurance company the probability that the total income from this business in one year is between 200,000 and 400,000.

We make $X$ mean the number of major accidents in a year, the probability of this happening

$$
p=0.005, X \sim b(5000,0.005)
$$

here

$$
n p=25, n p(1-p)=24.875,
$$

total proceeds is

$$
0.01 \times 5000-X=50-X,
$$

adjusted from the Centre Limit:

$$
\begin{aligned}
& P(20 \leq 50-X \leq 40)=P(10 \leq X \leq 30) \\
& =P\left(\frac{10-25}{\sqrt{24.875}} \leq \frac{X-25}{\sqrt{24.875}} \leq \frac{30-25}{\sqrt{24.875}}\right) \\
& =\Phi(1.003)-\Phi(-3.008) \\
& =0.8403
\end{aligned}
$$

And the probability of the insurance company losing money, 


$$
\begin{aligned}
& P(X>50)=P\left(\frac{X-25}{\sqrt{24.875}}>\frac{50-25}{\sqrt{24.875}}\right) \\
& \quad=1-\Phi(5.013) \\
& \quad=0.0000001698 .
\end{aligned}
$$

Thus, as long as the probability of an accident is low enough (0.005 in this case), such a business is almost guaranteed, which is why the insurance industry is happy to do so [5].

\section{Independence}

In recent years, the management industry has become popular. So, in management science, what problems can be discussed by probability theory? Two examples illustrate this.

Example I. Three underachievers did their homework independently, the probability of completion is

$$
P(A)=0.5, P(B)=0.2, P(C)=0.25
$$

which are the odds that at least one person will be able to finish the assignment if you put three people together?

By independence,

$$
\begin{aligned}
& P(A \cup B \cup C)=P(A)+P(B)+P(C)-P(A B)-P(B C) \\
& \quad-P(A C)+P(A B C)=P(A)+P(B)+P(C)-P(A) P(B) \\
& \quad-P(B) P(C)-P(A) P(C)+P(A) P(B) P(C) \\
& \quad=0.4+0.2+0.3-0.4 \times 0.2-0.2 \times 0.3-0.4 \times 0.3+0.4 \times 0.2 \times 0.3 \\
& \quad=0.616 .
\end{aligned}
$$

Visibly, "Two hands are better than one", the probability that solves a problem has greatly improved. It is enough to say that Mao Zedong, the first president of the People's Republic of China, once said that "more people make more power" and that "team spirit" is not unreasonable.

\section{Also for the team, who is more efficient?}

Example II Let's say we have 80 units of the same type of equipment, each unit works independently of the other, with a probability of failure 0.01 .There are two maintenance teams competing for maintenance, maintenance costs based on the number of people, a large number of teams paid high, a small number of teams paid low. Team A has four persons, each responsible for the maintenance of 20 equipment; Team B, three persons jointly maintain 80 equipment, whose efficiency, more worthy of appointment?

Team A: We make $X$ mean "number of 20 stations maintained by the first person that failed at the same time", we make $A_{i}(i=1,2,3,4)$ mean "20 stations maintained by the $i$-th person are out of order". The probability that 80 stations will fail to be repaired in time is

$$
P\left(A_{1} \cup A_{2} \cup A_{3} \cup A_{4}\right) \geq P\left(A_{1}\right)=P(X \geq 2) .
$$

And $X \sim b(n, 0.01)$, so

$$
\begin{aligned}
P(X \geq 2)=1-\sum_{k=0}^{1} P(X=k) \\
\quad=1-\sum_{k=0}^{1} C_{20}^{k}(0.01)^{k}(0.99)^{20-k} \\
=0.0169 .
\end{aligned}
$$

Team B: We make $Y$ mean "number of stations in 80 that failed at the same time", so $Y \sim b(80,0.01)$, and the probability that 80 stations will fail to be repaired in time is

$$
\begin{aligned}
P(Y & \geq 4)=1-\sum_{k=0}^{4} P(Y=k) \\
& =1-\sum_{k=0}^{3} C_{80}^{k}(0.01)^{k}(0.99)^{80-k} \\
& =0.0087 .
\end{aligned}
$$

The calculation found that team B was heavy (an average of about 27 units per person), but was 19.4 times more efficient than team a, while the cost was reduced (just 3 people). [6]There is no doubt that team B. There are many applications in the fields of communication, finance and so on.

\section{Variance}

If you have a million dollars to invest in, how do you manage your money? If you invest in business and stock, can you give a reasonable investment plan? Assuming that the two investments are independent of each other, the proportion of investment, return on investment and risk are shown in Table 2.

TABLE II. RELATIONSHIP BETWEEN INVESTMENT RATIO AND ANNUAL RATE OF RETURN AND RISK LEVEL

\begin{tabular}{ccc}
\hline Investment projects & $\begin{array}{c}\text { business } \\
\text { Percentage of } \\
\text { investments }\end{array}$ & stock $Y$ \\
\hline $\begin{array}{c}\text { Annual rate of return on } \\
\text { investments }\end{array}$ & $\mu_{1}$ & $1-\chi$ \\
Level of risk & $\delta_{1}^{2}$ & $\mu_{2}$ \\
\hline
\end{tabular}


$X, Y$ indicates their respective random returns, coefficient of correlation is $\rho$,portfolio income is $Z=x X+(1-x) Y$, average annual earnings is $E(Z)=x \mu_{1}+(1-x) \mu_{2}$, risk of the investment (variance) is

$$
\begin{aligned}
& D(Z)=D\{x X+(1-x) Y\} \\
& \quad=x^{2} \delta_{1}^{2}+(1-x)^{2} \delta_{2}^{2}+2 \rho x(1-x) \delta_{1} \delta_{2} .
\end{aligned}
$$

We want minimum risk. Let

$$
\frac{\partial D(Z)}{\partial x}=0
$$

we get

$$
x=\frac{\delta_{2}^{2}-\rho \delta_{1} \delta_{2}}{\delta_{1}^{2}+\delta_{2}^{2}-2 \rho \delta_{1} \delta_{2}}
$$

This would allow guaranteed returns to be achieved with minimal investment risk [7].

Practice shows that such probability theory can be widely used in economics. For example, the problem of unmarketable vegetables in the near future can be solved by a similar method, so as to guide vegetable farmers to determine the reasonable planting ratio and resist the risk of unmarketable vegetables.

\section{CONCLUSION}

Through the analysis of the above social hot spots, we will become the talent using probability theory in life. As Marx said, "A science is truly perfect only when it is successfully applied to mathematics". The introduction of such social hot issues into the teaching of probability theory will undoubtedly enhance students 'interest and enthusiasm in learning and lead them to take the initiative in using the knowledge of probability theory to solve the practical problems around them. When teachers teach theoretical knowledge of probability theory, if they can give corresponding examples in combination with the major they have studied, they can not only arouse the enthusiasm of students to learn, but also make them understand the rich background of the close connection between knowledge and human practice, so that they can experience the charm of mathematics. Einstein said, "Interest is the best teacher", to cultivate students 'interest in learning, learning results will be higher [8].

\section{ACKNOWLEDGMENT}

The work is supported by Project of Natural Science Foundation of Shandong province (ZR2016AM06).

\section{REFERENCES}

[1] O.B. Sheynin, Early history of the theory of probability. Archive for History of Exact Sciences.17 (3): 201-259.

[2] Bin Xie, Explain a few doubts with knowledge of probability. China Science and Technology Information, 2009(2): 240-242.

[3] F. Zhang, Application of probability in everyday life. Journal of Shanxi University of Finance and Economics: Higher Education Edition, 2007, 10(1): 243.

[4] Y.H. Long, Analysis of Typical Examples and Problems in Probability Theory and Mathematical Statistics. Beijing: Higher Education Press, 2004.

[5] Y.H. Yang, A Brief Discussion about the Application of Probability in Life. Introduction to Economic Research, 2010(18): 203-204.

[6] Z. Sheng, S.Q. Xie and C.Y. Pan, Probability Theory and Mathematical Statistics. Beijing: Higher Education Press, 2004.

[7] L.H. Wang, Application of probability statistics in economics. China Water Transport, 2010, 10(11): 68-69.

[8] C.B. Zheng, The Application of Probability Knowledge in Real Life. Journal of Shenyang Normal University: Natural Science Edition, 2010, 28(4): 470-472. 